\title{
The Role and Promotion Prospect of Air Volleyball in National Fitness
}

\author{
Wang Jingqiang \\ Basic Course Department, Hubei Business College, Wuhan 430070, China
}

Keywords: air volleyball; national fitness; promotion; universal

\begin{abstract}
With the methods of literature, questionnaire and comparative analysis, this paper analyzes the role of air volleyball in national fitness. The research shows that the air volleyball sports is suitable to be promoted in the middle ages. Air volleyball has a broad prospect in the national fitness program, but its popularity is not enough. It is suggested to follow the soft volleyball mode for market promotion, to strengthen the research and development of air volleyball and to strengthen the promotion of air volleyball.
\end{abstract}

\section{Introduction}

Since reform and opening up in China, people's most basic food and clothing problem is solved, the problem of food and clothing of the lives of most people focus from previous has shifted to the fitness exercise, more and more people are willing to put money [1], time and energy into the physical exercise. The economic development and social progress at the same time, brings people a superior and a life of ease, make people engaged in all kinds of physical activity time is greatly reduced, seriously affecting the national physical quality and health level, work competition, the fast pace of life, make people under tremendous pressure. In order to better promote the development of mass physical exercise, on June 20, 1995 of the state council promulgated the "national fitness program", a programmatic document issued, for the promotion of all-round, various physical exercise and the coordinated development of national economy, to improve the national physique, promote the national health service, to build fitness system with Chinese characteristics, and also provides the development of mass sports in China laws and regulations and the security of system. The number of sports people in a country, the proportion of the population, is closely related to the developed degree of the country. In the 21st century, more and more rich and colorful exercise program, making more and more people have free time in the leisure sports, which greatly increased the number of sports population in our country, but this part whether people can truly become a sports population, but also with their habit of exercise, exercise intensity, exercise time. Under the influence of competitive sports, the development of national fitness activities has become a guarantee for the sustainable development of China's mass sports. Nowadays, the development of sports in our country, the western developed countries have also developed various plans related to mass sports. The implementation of the "gold plan", as Germany has done, has made Germany a notable success in the development of mass sports [2].

According to the statistics, there are more than 150 million volleyball players in the world today. Volleyball has become a popular project after football, which is popular among the people of all countries. By our own gas volleyball volleyball is a not only maintains the features of athletics, and suitable for the middle-aged and old volleyball lovers continue to participate in athletic sports, is conducive to extend the service life of sports volleyball fan. Air volleyball has the characteristics of light weight [3], large volume and soft sphere, so that it is not restricted by gender, age and technical level, but can organize the activity participants without volleyball foundation to conduct primary competition. Gas volleyball to lower the movement skill, the characteristics of the game ball speed slow down, the ball back and forth the number of times increases, hit the ball pattern, beginners fear of the ball disappeared, and thus greatly improve the gas volleyball game interesting, attractive and ornamental. Through the research, it is confirmed that the volleyball sport plays a certain role in the national fitness, discusses its promotion prospect, and puts forward some Suggestions for better promotion and popularization of the air volleyball. 


\section{Study Subjects and Methods.}

\subsection{Research object}

In fujian province, there were 327 retired people (all of them are the main or the only exercise program). The duration of exercise was more than 3 years, and the average activity was about 3 times per week.

\subsection{Research methods}

The methods of literature, investigation, comparison and analysis were used.

\section{Results and Analysis}

The role of air volleyball in national fitness.

\subsection{Effects on neurological and cardiovascular function.}

Gas volleyball is a comprehensive and aerobic exercise related projects, it can stimulate and improve the analysis of human body each organ function, delay the decline of each organ system, persistent exercisers, can delay the ability of oxygen to brain cells, constantly stimulate and adjust the intensity of brain nerve activity process, balance and flexibility, can make the elderly more as and can. Through many years of exercise, participants generally felt that their overall ability to respond to their hand, foot, vision and hearing improved. America, German medical experts pointed out: "arch is the second heart" the human body, through the role of mechanical force [4], improve and improve the blood circulation of human body each organ system, especially the ability of oxygen to the brain blood circulation and cell. Therefore, air volleyball has a significant effect on delaying senile dementia. Participating in air volleyball can improve the mental state and strengthen the constitution, restore the ability of thinking creation and rejoin social activities, and more reflect the fitness value of air volleyball for the aged. The old people have been engaged in the sports of air volleyball, and the health condition is better than that before the air volleyball. The investigation revealed that some of the members of the team who had suffered from some chronic diseases were now in better condition, with fewer drugs or fewer times. Apart from a few minor sports injuries caused by improper exercise, no other negative effects of exercise have been observed.

\subsection{Promote mental health.}

The world health organization (who) put forward the new concept of health [5]: "health is a physiological, psychological and social status, health not only refers to a person without symptoms or disease, and must have good body at the same time, the full spirit and address social communication". Old man retired, scope and greatly reduce the amount of social activities, family transaction volume has increased sharply on the role of life change, some people in the physical, psychological slow to adapt to, especially caused by loss of emotional distress, depression, anxiety and other emotional surge, the doctor of traditional Chinese medicine of "physical and mental diseases. If simple fitness, in order to prolong the life, and do not pay attention to the health care, it is difficult to achieve the rest of the life, the longevity, the end of the end of the purpose. By taking part in the exercise of the air volleyball, the mood of the group conversation, the people in the exercise is particularly happy, which enriches the content of life, and obtains the psychological "spiritual nourishment tonic". Medical and psychological confirmation: physiology or pathology can affect psychology, and psychology can also affect physiology and pathology. In the process of exercise, laughter is also a versatile body movement, laughter can establish a good psychological environment, eliminate the psychological bad mood, and rebuild the unbalanced psychology. It can be seen from this that the old people participate in the sports of air volleyball, not only the fitness and recreation of the body and mind. Improve social ability, eliminate age gap, and have greater fitness value, which reflects the role of air volleyball in national fitness. Through the establishment of public elective courses of air volleyball, it is found that college students are very fond of the sport of air volleyball. The important reason is that the air volleyball has a strong interest. Students 
learn skills and exercise in laughter and laughter. Participating in air volleyball plays a certain role in improving students' social ability, cultivating their feelings and relieving stress.

\section{The Popularization of Air Volleyball}

\subsection{The popularization of air volleyball sports}

Gas volleyball is very suitable for sports and fitness levels of ordinary group, at the same time, gas volleyball, although the ball weight loss, reduce the height of the net, narrow space, increase the stroke frequency, density, but no technical content is reduced, the participants because of the skill strong self-confidence and are particularly interested in. Therefore, gas volleyball accepted and loved by the participants, in some regions and units to carry out the situation well, such as jiangsu, anhui, jiangxi, fujian, zhejiang, guangxi and other provinces and the rail system). Take xiamen, fujian province, zhangzhou, quanzhou and putian cities as examples, these cities hold many kinds of air volleyball competitions, such as different systems, industries or mixed types. In the early days of the volleyball, the city was brought to the villages and towns by the city. According to the research of longhai city of fujian province, liang-fon estate located some villages and towns, the elderly TiXie special gas volleyball, residents here watching gas volleyball like guangdong taishan people watching "nine men volleyball" spontaneous and enthusiastically. The elderly association of each county in zhangzhou has agreed to take turns to hold the quarterly air volleyball cooperation competition in each district, and promote the technical exchange and improvement of the gas volleyball. The national volleyball training base is located in the city of zhangzhou city, where there are many elderly popular volleyball teams, and they have been trained three times a week in the middle school gymnasium. Some volleyball amateur, middle age due to busy with work and lack of physical and stop the volleyball movement, later had the opportunity to participate in gas volleyball, to return to the stadium, the survey also found that over a few years, still cheerfully to participate in the activities.

\subsection{Air volleyball is suitable for popularizing in the middle ages and in all age groups.}

Air volleyball originated in elderly activities, but should not be confined to the elderly population. All the men and women of air volleyball can take part in the competition, the adult colleges and universities, enterprises and institutions in the grass-roots sports competition, the fraternal unit activities, the travel, and the best practice. In the indoor volleyball match, the two sides need a lot of 12 people, the number of requirements is more, and the technical requirements are higher. Air volleyball is like a portable indoor volleyball. It is fast and entertaining, and it is relatively easy to organize games for communication, which is naturally favored by volleyball fans of all ages. The example shows that the project of air volleyball can prolong the public participation in volleyball for $20 \sim 30$ years, which is one of the lifelong sports. The research shows that the air volleyball has gradually entered the school and other units, and has held a variety of college students and on-the-job participation competitions. In April 2006, the channel women's fitness competition held in xiamen was one of the events in the competition, which attracted many teams, including Hong Kong and Taiwan, to participate in the competition. It has been proved that the sport of air volleyball is also suitable for all ages other than the elderly. It is reported that sichuan province has included it in the teaching content of middle and primary school physical education.

\subsection{Popularize the problems existing in air volleyball.}

Due to gas volleyball history is shorter, superior function has not been widely known by people, to the professionals in it, combined with the media publicity, rarely, so the current popularization gas volleyball is still has some problems. It is suggested that the local authorities should properly distribute the proceeds of sports lottery to support the construction of local air volleyball venues.

Promotion and competition activities are included in the plan to support the faster and better development of air volleyball. The lack of social attention is the objective cause of the further promotion and popularization of the volleyball sport, but there are many subjective factors :(1) the 
promotion channel is too centralized. So far, China's air volleyball has been mainly organized by the elderly association, mostly in the elderly population. Although there are non-elderly people involved, both the number and scale are very limited. "Wine and incense are also afraid of the depth of the alley". Only the functions of education departments and sports functions at all levels can be fully utilized to promote and popularize the "official" multi-channel to different groups. As a Chinese invention of sports, our goal is not only wants to be popularized in China, and to introduce to the world this was before the movement of the international Olympic committee President Juan Antonio samaranch affirmed and praised. Old TiXie it is understood that the ministry of railways has gas volleyball in southeast Asia, made for gas volleyball the first step on the road to the world, but only by the ministry of railways old TiXie independently to the important task of introducing gas volleyball world is clearly not too realistic. (2) there are certain defects in the competition rules. Since the main participants in the current air volleyball movement are the elderly, the rules are formulated to "limit competitiveness, highlight safety and entertainment". With the participation of other age groups, certain elements of the existing rules, such as restrictions on blocking, appear to be inappropriate. It is suggested to modify and perfect the whole participants in the premise of maintaining the characteristics of air volleyball, or make different competition rules according to the age characteristics of the participants. (3) the quality of air volleyball is more serious. Gas relative indoor volleyball volleyball has obvious disadvantages in the life, often appear burst, deformation, leakage phenomenon, although there is price advantage (unit cost 10 yuan), but the quality issue has become

One of the factors hindering the further promotion and popularization of air volleyball. It is suggested that the manufacturer should improve the characteristics of air volleyball.

\subsection{Thinking about developing the sports industry of air volleyball.}

The sports industry is a part of sports that can operate according to the industry and provide products to the society. Former premier zhu rongji in the ninth National People's Congress second conference of government work report points out: to actively guide the residents to increase consumption culture, entertainment, fitness and travel, it marks the sports industry in stimulating domestic demand, promoting my economic development the role has been the central leadership's recognition and attention. Take the elderly sports industry for example: the projections show that China is the world's oldest and fastest-growing country. In 2008, China's population aged 60 and over will reach 134 million, or $12.48 \%$ of the total population. In 2030, the elderly population will reach 310 million, and the share of the total population will rise to $20.42 \%$. In 2050, the proportion of the elderly population of 468 million will increase to $27.7 \%$. China's existing the elderly over the age of 60 speed increase by $3 \%$ a year, to meet the demand of the elderly will continue to increase, the proportion of elderly population accounts for the consumer market share will be more and more big, the development of the elderly sports industry will also be necessary. As an old and young sport, air volleyball is very large and attractive in the domestic market, and its potential commercial and commercial value is self-evident. However, the research indicates that there are few existing gas volleyball manufacturers in China, and the quality is uneven. Existing in how to successfully mining emerging sports business value, yong Lin sporting goods co., LTD., Beijing has made a successful example for everyone: first invested heavily in the promotion and popularization of soft volleyball, cultivate soft volleyball market, and then get huge returns, and formed a "to promote sales promotion" virtuous circle. There are many similarities between air volleyball and soft volleyball. In some respects, it has certain advantages.

\section{The Role of Air Volleyball in National Fitness.}

As a sports, gas volleyball naturally have all sports exercise can have value, and because gas volleyball is a form of mass sports, therefore, gas volleyball has its entertainment group cooperation. In addition, due to the rules of gas soft volleyball ball, moderate exercise, broad and studious and easy to understand, suitable for people of all ages fitness, can appear in different students of sports in the classroom, education significance. 


\subsection{Keep fit}

Air volleyball is a comprehensive movement that can balance hand, foot, eyesight and hearing. It is a form of aerobic exercise. As is known to all, sports can stimulate human potential, delay the aging of human body organs and improve the function of the human body organ systems, especially to stimulate the vigor of brain cells, brain and body the organic degradation, the elderly has an extremely important role to the health of human body, gas volleyball as a sport is no exception. According to the author

Interviews and surveys found that people who stick to a volleyball sport have improved their limbs and senses than their peers who did not participate in sports. Therefore, it is helpful to strengthen the exercise of air volleyball, which can help the body to be healthy and have the effect of bodybuilding.

\subsection{Entertain}

Air volleyball is a form of mass sports, so it is also an entertainment for group cooperation. By taking gas narrowing movement, participants in addition to being able to exercise their bodies, outside to enjoy the fun of their own body movement, also can exercise experience in sports exchange with others, talk not only improved the psychological mood of exercisers in laughter, enriches the life interest, and can have the purpose of entertainment. In addition to the participants, do not directly participate in the chi movement.

Viewers can feel physical and mental pleasure, from the athletic gas narrow rules broad and simple game, low technical, so viewers can quickly into the game, enjoy viewing pleasure out of sports competitions. The movement of the gas lead the participants to exercise the body, free the body and mind in the laughter, and also make the viewer unburden the pressure and have a rare entertainment effect.

\subsection{Education}

Air volleyball is not only a popular sport for middle-aged and old people, but also applies to education. Because gas volleyball rules of soft ball, moderate exercise, broad and studious and easy to understand, therefore, is suitable for people of all ages the movement fitness, can appear in different students of sports in the classroom, education significance. The volleyball teaching course in our country, the students accounted for a large proportion of the physical education class, due to the complex rules of volleyball, flap or the game because of the quality of a material is hard too hurt, student's study enthusiasm greatly affected, the current sports volleyball course met difficulties in the classroom. In the course of my visit to the school curriculum, the author is now offering a sports course for air volleyball. The students are more interested in the high security and easy to understand sports. In the sports class of air volleyball, students not only strengthen physical training, learn sports skills, but also learn teamwork and cultivate sentiment. Therefore, it can be seen that the use of air volleyball is suitable for sports programs of all ages, which can not only exercise the body, but also have education significance.

\section{Conclusion and Suggestions}

Youth age and the characteristics of psychological development, make them curious about new things with, to have new psychological characteristics, and gas volleyball is a new and entertaining sport, therefore, better able to stimulate students' interest in learning, students in physical education, sports participation enthusiasm. According to the physical and mental characteristics of primary and middle school students and the development of physical training, the leisure of physical exercise is the development trend of the future primary and middle school physical training. At present, the gas volleyball in the community and the wider university campus to carry out very little but in primary and secondary schools to carry out, therefore, gas volleyball to healthy development in the primary and secondary schools, the first thing to incorporate gas volleyball sports in elementary and middle schools sports curriculum system, introducing gas volleyball class. In today's national fitness 
program, children are the focus of national fitness, and it is an inevitable trend to focus on developing sports backbone among teenagers. At the same time, the development of air volleyball in middle school has laid a solid foundation for the development of competitive volleyball in China, so that the mass sports and school sports can better promote the development of competitive sports.

(1) the air volleyball sport has a high fitness value and is suitable for the promotion of people of all ages.

(2) the air volleyball movement is mainly carried out among the elderly in my current stage, and the popularity is not enough.

(3) air volleyball has a good market development prospect, which can be used in the market promotion of soft volleyball mode.

(4) strengthen the research and development of air volleyball, further improve its grade and quality, so as to facilitate better popularization and popularization.

(5) when conditions are ripe, the promotion of air volleyball can be strengthened to enhance its influence in the international arena.

\section{References}

[1] Kühl A, Balinova N, Bykova E, et al. The role of saiga poaching in rural communities: Linkages between attitudes, socio-economic circumstances and behaviour[J]. Biological Conservation, 2009, 142(7):1442-1449.

[2] Mamut J, Tan D Y, Baskin C C, et al. Role of trichomes and pericarp in the seed biology of the desert annual Lachnoloma lehmannii, (Brassicaceae)[J]. Ecological Research, 2014, 29(1):33-44.

[3] Grundler P V, Brugger J, Etschmann B E, et al. Speciation of aqueous tellurium(IV) in hydrothermal solutions and vapors, and the role of oxidized tellurium species in Te transport and gold deposition[J]. Geochimica Et Cosmochimica Acta, 2013, 120:298-325.

[4] Timpka S, Petersson I F, Zhou C, et al. Muscle strength in adolescent men and risk of cardiovascular disease events and mortality in middle age: a prospective cohort study[J]. BMC Medicine, 2014, 12(1):1-8.

[5] Luthra S, Obert J P, Kalonia D S, et al. Biochemical performance of native and introduced clam species living in sympatry: the role of elements accumulation and partitioning[J]. Marine Environmental Research, 2015, 109(1):81.

[6] Baiden P, Dunnen W D, Arku G, et al. The role of sense of community belonging on unmet health care needs in Ontario, Canada: findings from the 2012 Canadian community health survey[J]. Journal of Public Health, 2014, 22(5):467-478. 